\title{
Benchmarking of Undergraduate Computing Curricula in Kenya
}

\author{
Mungai Joseph and Wanjiku Ng'ang'a \\ School of Computing and Informatics, University of Nairobi P.O. Box 30197, G.P.O Nairobi Kenya \\ j.mungai@hotmail.co.uk \\ School of Computing and Informatics, University of Nairobi P.O. Box 30197, G.P.O Nairobi Kenya \\ wanjiku.nganga@.uonbi.ac.ke
}

\begin{abstract}
This study investigated the quality of undergraduate computing curricula at Kenyan universities, how they compare locally and regionally with equivalent programs and how closely they meet the ICT sector needs. It was guided by four objectives i.e. to undertake an ontological mapping of computing curricula, to identify appropriate benchmarking criteria, to develop and test a benchmarking tool, and to investigate the alignment of these curricula to computing skills requirement. The study was deemed important by the plethora of academic computing programs of varying degrees of utility and credibility, which are a product of the escalating demand for computing education in Kenya given the development of Vision 2030 and the rapid growth of the ICT industry. To achieve its objectives, the study adopted a quantitative and qualitative crosssectional descriptive survey of computing curricula offered locally (in Kenya) and regionally (from best practicing countries, USA and India). A sample of $70.3 \%$ was drawn from the target population for ontological mapping. Two research instruments, i.e. a questionnaire and a document analysis framework that were administered to a cross-section of 11 public/private universities. The study established that there are 24 undergraduate computing programs under 6 titles, viz. BSc., BCom., BTech., BB., BEd. and BEng. The two most populous programs are BSc. Computer Science (CS) and BSc. Information Technology (IT), which were selected to help identify two benchmarking criteria: Percent weight allocation of core hours within ACM knowledge areas and Relative performance capabilities of computing graduates. Using these criteria a benchmarking tool was developed and tested, which depicted disparities among the respondents in the percent weight allocation of core hours in CS programs. Similarly, it portrayed overlaps in the relative performance capabilities of CS and IT graduates, an outcome that queried the uniqueness of these programs. As such, its results indicate that the quality of the two computing programs is relatively insufficient. However, it further establishes that the computing curricula are aligned to meet the top 3 highly demanded computing skills i.e. Networking, Software development and Internet skills albeit insufficient percent weight allocation of core hours in Software development. It therefore recommends further testing and refining of the established benchmarking tool, the need to re-focus the computing programs and supports the call to institute a regulatory body and qualifications framework for computing education and skills.
\end{abstract}

\section{Indexing terms/Keywords}

Benchmarking, Computing, Standards, Higher Education, Quality Assurance, Accreditation

\section{Academic discipline and Sub-disciplines}

Science; Information Technology

\section{Subject classification}

Computer Science, Information Technology, Computing

\section{Type (Method/Approach)}

Descriptive Survey; Questionnaires; Document Analysis; Benchmarking

\section{Council for Innovative Research}

Peer Review Research Publishing System

Journal: International Journal of Management \& Information Technology

Vol. 6, No. 1

editor@cirworld.com

www.cirworld.com, member.cirworld.com 


\section{INTRODUCTION 1.1. ICTs and Development}

There is increasing importance of ICTs (Waema, 2002; Dutta, Lanvin, and Paua (eds.), 2003) and Higher Education (Lacrin and Karkkainen 2009) in transforming traditional economies (Agricultural and Industrial) into knowledge-based economies. Some countries have as a result of developing ICT policies and strategies that integrate ICTs into their national development agenda leapfrogged their development to increase productivity and transform into knowledge societies. These include Singapore, South Korea, Rwanda and South Africa. Similarly, the Government of Kenya (GOK) has initiated major steps to promote ICT use in Vision 2030 (GOK, 2007) and its National ICT policy (Waema, 2005). However, this endeavor is impeded by the lack of adequate human capacity in ICT (Waema, 2002; Waema, 2005). This has been attributed to the use of disparate and non-standardized curricula and the disconnect between industrial and national developmental needs, among others (Waema, 2002).

\subsection{Higher Education}

In order to permit the mobility of qualifications and labor into the global economy, aligning the Higher Education (HE) curricula with developed economies' models has been among the key interventions (World Bank, 2008 Cited in Buckner, 2011). Consequently, ranking of universities has emerged in the last decade as a global phenomenon that enables institutions to compare how well they are doing with respect to others globally. Such include; Academic Ranking of World Class Universities (since 2003) and Times Higher Education Supplement World Rankings (since 2004), among others. Global university rankings and ratings have not only stimulated competition among but also seek to differentiate types of institutions, and their programs / disciplines. They are a potent device for framing HE on a global scale and are a key driver of international competitiveness, thus the need to make them objective, transparent, free of self-interest and methodologically coherent (Inter-University Council of East Africa (IUCEA) and Deutscher Akademischer Austausch Dienst (DAAD), 2010).

\subsection{Problem statement}

Kenya aspires to become a globally competitive and prosperous nation as spelled out in its Vision 2030 blueprint, by achieving an initial 10\% GDP in the ICT sector, among other initiatives (GOK, 2007). This vision and the rapid growth of the ICT industry have escalated the demand for computing education (Alemneh and Hastings, 2006; Kashorda, 2006). Consequently, a plethora of academic degree programs and training curricula of varying degrees of utility and credibility have been developed and used, which present two key problems, the need to determine (i) the quality and (ii) academic differentiation of these programs/curricula. Similarly, most university academic programs have not reached excellent levels in the global professional accreditation standards and market scale owing to their downward trend in their quality of education and lack of peculiar characteristics (Magutu et. al., 2011). This is attributed to the lack of international benchmarking of their processes, products / services and as a result impedes the mobility of staff, students and programs. Thus, benchmarking which was the core remit of this study provides a means to ascertaining quality assurance in Higher Education.

\subsection{Study objectives}

The study investigated the quality of computing curricula at universities in Kenya, how they compare locally and regionally with equivalent programs and how closely they meet the ICT sector needs and the national development agenda. Specifically, the study:

i. Undertook an ontological mapping of computing curricula offered locally

ii. Identified appropriate benchmarking criteria for evaluating these programs.

iii. Developed and tested a benchmarking tool that to evaluated and characterized computing disciplines.

iv. Investigated how well the major computing curricula were adapted to computing skills requirements in the local ICT industry and Vision 2030.

\subsection{Review of literature}

\subsubsection{Knowledge Economy}

In the 1970's Organization for Economic Co-operation and Development (OECD) economies began transiting economically from manufacturing-based to service-base orientation (OECD, 2011). As a result, there was reduction of the relevance of traditional factors of production (labor and capital) with knowledge becoming the driver of productivity and economic growth (Verlayudhan, 2012). Thus, in the emerging knowledge economy, computer literacy and access to network facilities have surpassed the need for literacy in the traditional sense (OECD, 2011). Newly industrialized countries (e.g. Singapore and South Korea) have employed ICTs to make gigantic improvements in both productivity and quality, in the fight against poverty. To leapfrog its development, Kenya needs to address key challenges in the ICT sector, which include insufficiency in computing skills besides the disparate levels of training, duration and content (Computer Society of Kenya (CSK), 2006; Waema et. al., 2009; Business Process Outsourcing - Skills Task Force (BPO-STF), 2010; International Development Corporation (IDC), 2011; Ventures Africa, 2012).

\subsubsection{Motivations of Benchmarking}


Benchmarking was initially employed as a quality improvement practice at Xerox Corporation in response to increased competition and a rapidly declining market share (Camp, 1989), which revived its competitiveness. Although, it initially aimed at combating competition it has since proliferated other sectors including health care, government, and education (Camp and Andersen, 2004). In fact, its focus now incorporates non-competitors and industrial outsiders in learning how to improve business processes. Other key impetus of its practice are the publication of various texts on benchmarking, pursuit of international competitiveness, growth of the quality 'movement and the rapid growth of ICT.

\subsubsection{Benchmarking Higher Education}

Benchmarking in Higher Education Institutions (HEls) thrives on the emphasis of collegiality and recognition of the international role of universities. This was traditionally manifested in professional associations, inter-institutional visits, functions of professional bodies, and accreditation processes (Schofield, 1998). Albeit minimal, proliferation of the practice in $\mathrm{HE}$ reflects the search for a more effective way of regulation, continuous improvement and innovation (Jackson, 2000 Cited in Magutu, et al, 2011). Across Europe, benchmarking has been done through the EU Bologna Process, which seeks to promote curriculum reform, quality assurance, qualifications frameworks \& recognition, mobility and social equity in the European Higher Education (Center for Higher Education Policy Studies (CHEPS), 2008). In the USA, the practice has elicited a number of publications (Farquhar, 1998) while in the 1990's, benchmarking HE was visible in Australia in pursuit of quality assurance (Bridgland and Goodacre, 2003) and the promotion of efficiency and effectiveness in operations.

In Africa, the Inter-University Council for East Africa (IUCEA) has been instrumental in spearheading the Quality Assurance initiative with the support of the German Academic Exchange Program (IUCEA and DAAD, 2010). Attempts have been made to focus on mutual recognition of qualifications to enhance degree comparability, graduate mobility and employability within Africa and beyond. These include, the Arusha Convention (ratified in 1981), the Nyerere programme, the Pan African University, the Africa HE Harmonization and Tuning Project (Tuning Africa, 2011). For instance, the Tuning Project emphasizes the need to design and develop curricula to produce graduates with integrated skills and competencies, being flexible, independent, creative and innovative thinkers and job creators.

\subsubsection{Computing Education Standards and Trends}

A number of professional organizations exist that promote computing education, both as a Science and Profession through developing computing curriculum guidelines for HE. They include; Association for Computing Machinery (ACM), Institute of Electronic and Electrical Engineering - Computer Society (IEEE-CS), Association of Information Systems (AIS), and Association for Information Technology Professionals (AITP). Their publications provide the body of knowledge for undergraduate programs in 5 computing disciplines; Computer Engineering (CE), Computer Science (CS), Information Systems (IS), Software Engineering (SE) and Information Technology (IT). Their publications (ACM and IEEE-CS, 2006) note that there is rapid expansion of the computing field. The ACM Computing Curricula Series (2008) adopted in this study as the 'standard' is hinged on the North American education system and has been adopted by the EU Bologna process owing to its global strength (Borzovs, 2004). It is considered as the de facto standard computing curriculum.

\subsubsection{Benchmarking Types and Methods}

The following four benchmarking methodologies/tools were reviewed, whose outcome informed the design of the benchmarking tool developed and tested in this study:

i. Benchmarking of Engineering with Conceive, Design, Implement, Operate (CDIO) Curriculum (Bankel et. al., 2005).

ii. Comparisons of Graduate Software Engineering Curriculum 2009 (GSwSE2009) to current Masters' programs in Software Engineering (Frailey, Ardis and Hutchison, 2009).

iii. Surveys of Enacted Curriculum (Porter and Smithson, 2001)

iv. Accreditation Board for Engineering Technology (ABET) 2012-2013 Criteria for Accrediting Computing Programs (ABET, 2011).

To achieve its aim, this study adopted a hybrid of the GSwE2009 comparison template and the ABET evaluation criteria as the others had resource constraints, inherent subjective definitions, specificity in design, lacked portability, and lacked the required taxonomy.

\section{MATERIALS AND METHODS}

\subsection{Study design, population and sampling procedure}

A cross-sectional descriptive survey of computing curricula offered locally (in Kenya) and regionally (from best practicing countries, USA and India) was employed. The total research population consisted of 63 colleges/universities, categorized into; 7 Public universities, 24 Public university constituent colleges, 14 Chartered Private universities, and 18 Private universities/constituent colleges (Commission of Higher Education (replaced by Commission of University Education, in 2013) $\mathrm{CHE}, 2012$ ). The last 18 institutions were excluded from the study for not offering computing programs. Data was collected on the various computing programs offered collected from 45 participating institutions from which the two programs (CS and IT) were selected to identify benchmarking criteria and develop and test a benchmarking tool. Stratified sampling procedure was adopted in selecting the representative institutions offering these two programs. 
This procedure provides high statistical precision as compared to simple random. The two programs were selected based on their high popularity among the universities, besides the availability of ACM standards.

\subsection{Data collection methods and research tools}

A questionnaire and framework for curricula analysis were developed using as a hybrid of inputs from ACM and IEEE-CS (2006), ABET evaluation criteria and GSwE2009 comparison document. Secondary data on computing courses offered by the 45 institutions was obtained from the CHE (2012) report (for private universities) and the Joint Admissions Board (replaced by Kenya Universities and Colleges Central Placement Service, in 2013) JAB, 2012/2013 intake (for public universities and constituent colleges). Other data was collected from relevant curricula documents including syllabi, university prospectuses and websites. Primary data was collected using questionnaires (online and hard copies).

\subsection{Data analysis}

Quantiative data was input in tables on MS Excel ${ }^{\circledR} 2007$ and SPSS ${ }^{\circledR}$ version 16 for statistical coding and analysis to obtain simple descriptive uni-variate statistics to draw inferences and comparisons of the measured variables. During editing the raw data from the surveys was examined to detect errors and omissions. In coding the data was classified, sorted and tabulated for easier comparison and inference. Document analysis of the curricula was done using a framework that heavily anchored on the ACM knowledge areas. NVivo ${ }^{\circledR}$ version 10 was used to query the word frequencies in a sample curriculum and match it against the ACM knowledge areas to establish its 'best fit'.

\subsection{Reliability and validity of data collected}

Internal validity was achieved through controlling internal and external influences i.e. proper orientation of research assistants. Similarly, external validity was achieved by following correct sampling procedures (that avoid bias) and using a representative sample size (at least $30 \%$ ). In this study, data validity was ensured by collecting data from reliable sources (senior faculty as respondents), using basic questions as identified in the related literature review, and pre-testing the questionnaire for meanings.

\section{RESULTS AND DISCUSSION}

\subsection{Study sample and phenomena}

The study established that there were 24 undergraduate computing programs falling under 6 titles: Bachelor of Science (BSc), Bachelor of Commerce (BCom), Bachelor of Technology (BTech), Bachelor of Business (BB), Bachelor of Education (BEd), and Bachelor of Engineering (BEng).

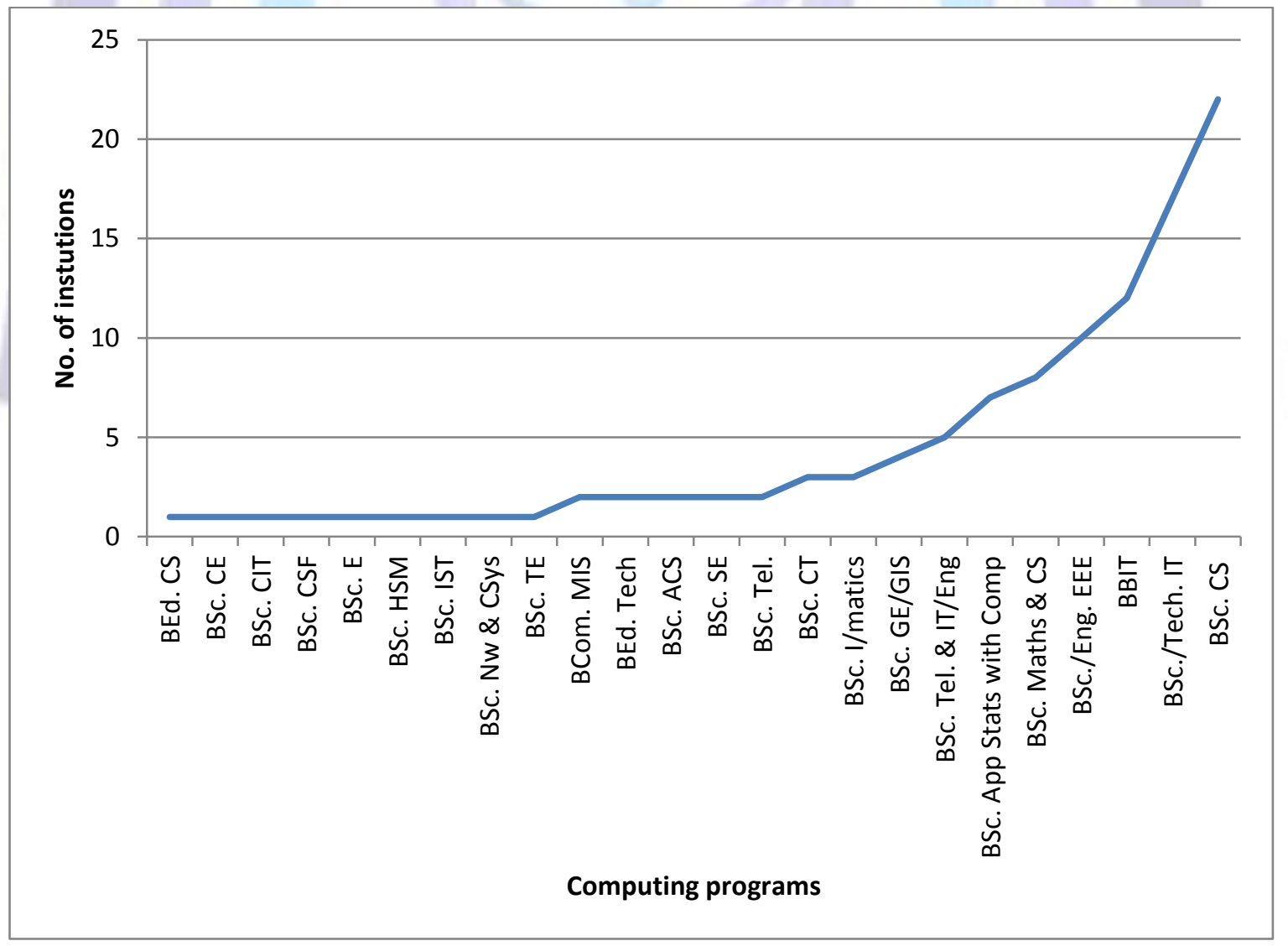

Figure 3.1: Computing programs offered by Public and Private Universities/colleges 


\section{Acronyms}

BEd. Computer Science (BEd.CS); BSc. Computer Engineering (BSc.CE); BSc. Computer Information Technology (BSc.CIT); BSc. Computer Security and Forensics (BSc.CSec \& Fr); BSc. Electronics (BSc.E); BSc. Health Systems Management (BSc.HSM); BSc. Information Systems Technology (BSc.IST); BSc. Networking and Computer Systems (BSc.N/w \& CS); BSc. Technology Education (BSc. TE); BCom. Management Information Systems (BCom.MIS); BEd. Technology (BEd. Tech); BSc. Applied Computer Science (BSc.ACS); BSc. Software Engineering (BSc. SE); BSc. Telecommunications (BSc.Tel); BSc. Computer Technology (BSc.CT); BSc. Informatics (BSc.I/matics); BSc. Geomatic Engineering/Geospatial Information Systems (BSc.GE/GIS); BSc. Telecommunications \& Information Technology /Engineering (BSc.Tel \& IT/Eng); BSc. Applied Statistics with Computing (BSc.App Stats with Comp); BSc. Maths \& Computer Science (BSc.Maths \& CS); BSc./Eng. Electrical \& Electronic Engineering (BSc.EEE), BB Information Technology (BBIT); BSc./Tech. Information Technology (BSc./Tech.IT); BSc. Computer Science (BSc.CS)

The findings show that BSc. CS was the most popular followed by BSc/Tech. IT. Further, in the public universities BSc. CS was most popular while BBIT was most popular among private universities. This disparity insinuates a possible divergence in the prevailing conditions. Notably, IS, CE and SE, are least popular, a factor could be a drawback given the GOK's Science Technology and Innovation (STI) policy framework that aims to generate knowledge and innovation. However, the increase in the variety of computing programs may be attributed to developments in the application domains of CS in robotics, computer vision, intelligent systems, decision support systems and bioinformatics.

\subsection{Benchmarking criteria}

Two benchmarking criteria were adopted from the related studies for comparing the (test) curricula from the respondent institutions with each other, and against the reference (ACM and All India Council for Technical Education (AICTE)) curricula. These are as below:

\section{i. $\quad$ Percent weight allocation of core hours within ACM knowledge areas}

\section{a. Computer Science}

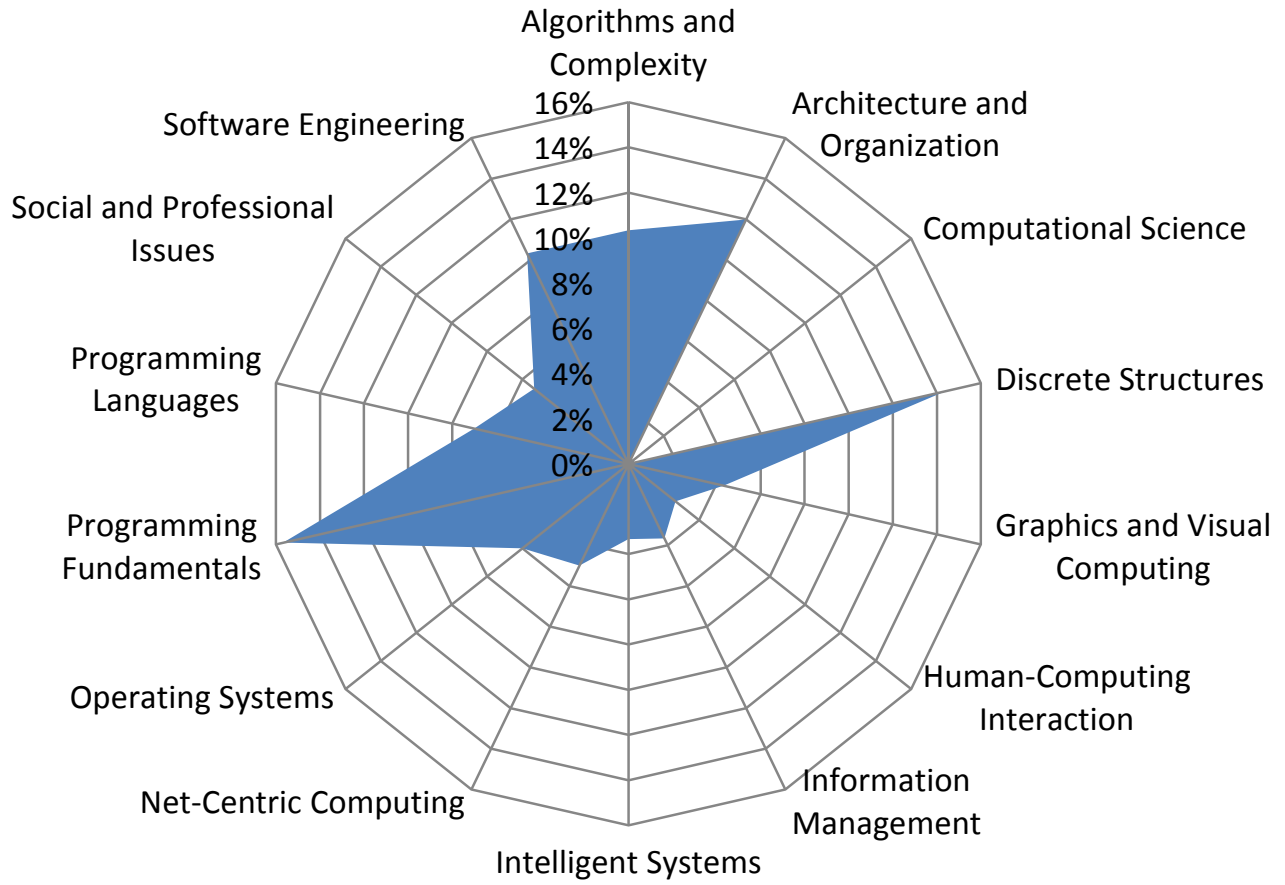

Figure 3.2: Percent weight allocation of core hours in CS program - ACM

Arguably, Figure 3.2 shows that the ACM CS curriculum has been designed with highest emphasis in Programming Fundamentals (16\%) and Discrete Structures (14\%). It appears to least prioritize Intelligent Systems (3\%) and Computational Science $(0 \%)$. 


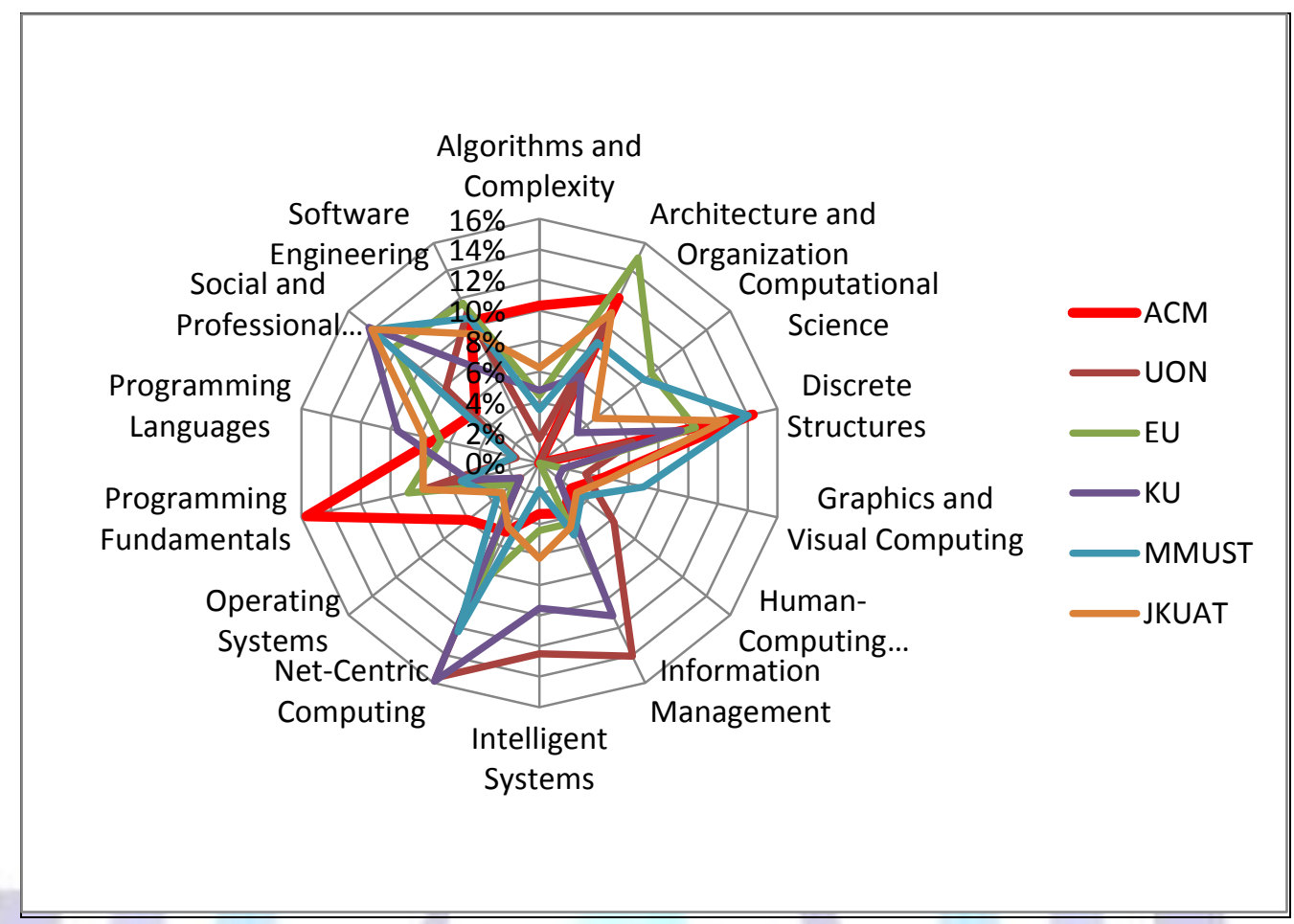

Figure 3.3: Percent weight allocation of core hours in CS program - ACM vs Respondents

\section{Acronyms}

University of Nairobi (UON); Egerton University (EU), Kenyatta University (KU); Masinde Muliro University (MMUST); Jomo Kenyatta University of Agriculture and Technology (JKUAT)

Figure 3.3 shows a similar mapping of the CS programs by respondent institutions onto the ACM knowledge areas. This data shows content divergence among the curricula. For instance, the highest prioritized knowledge areas are disparate among the respondents. However, relative congruence is observed in 3 knowledge areas between the respondents and ACM curricula: Discrete Structures, Software Engineering, and Architecture and Organization.

\section{b. Information Technology}

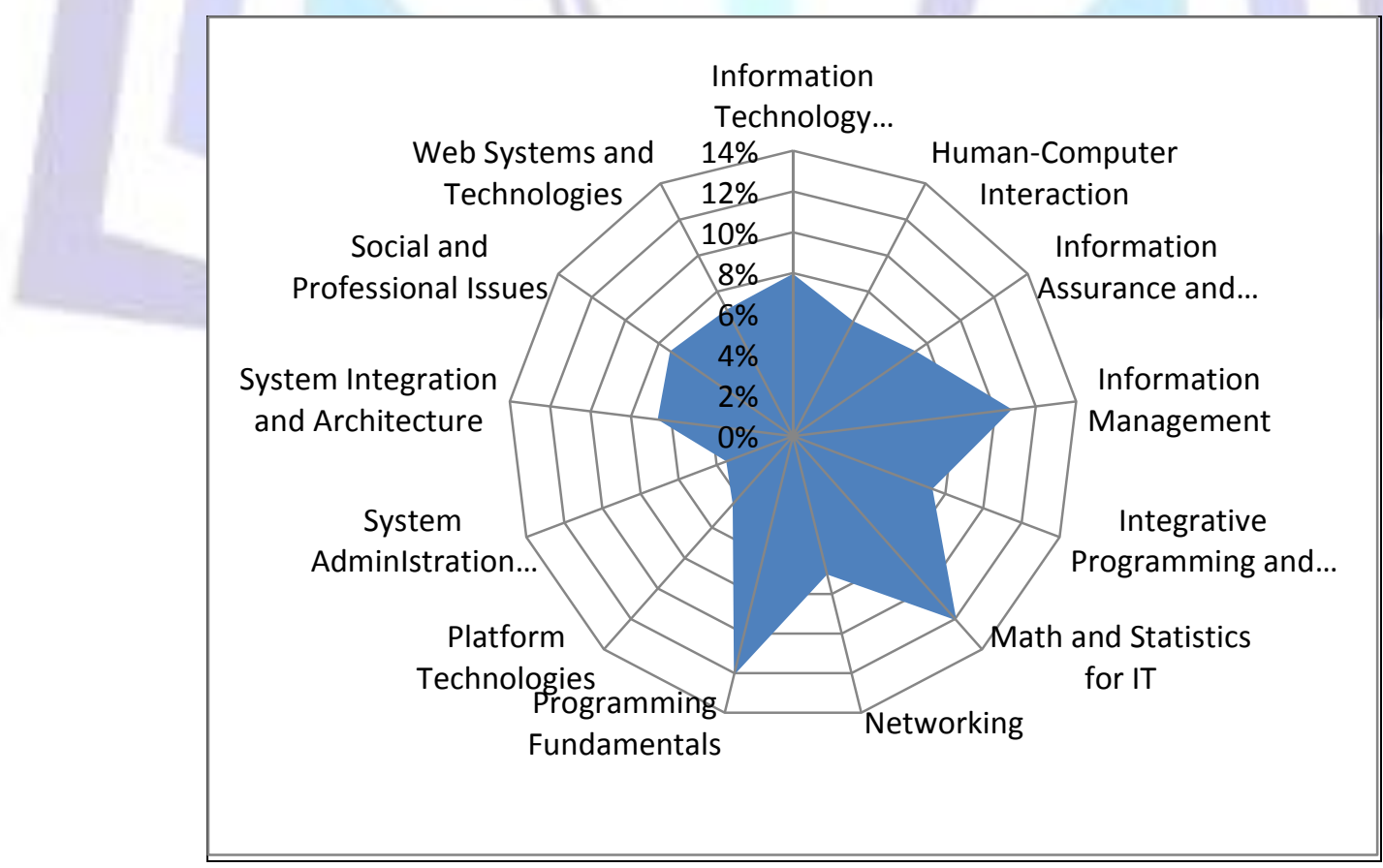

Figure 3.4: Percent weight allocation of core hours in IT program - ACM

Figure 3.4 shows that the ACM IT curriculum is designed to have highest emphasis in Maths and Statistics for IT (12\%) and Programming Fundamentals (12\%) knowledge areas. Low emphasis is placed on Platform Technologies (4\%) and 
System Administration and Maintenance (4\%) knowledge areas. Figure 3.5 shows how the percent weight allocation of core hours compares between the ACM and sample IT curricula. Evidently, the sample curricula exceed ACM by at least 3 times in the weighting of Social and Professional Issues. Similarly Integrated Programming and Technologies is under weighted in the test curricula $(\leq 2 \%)$ as compared to ACM $(7 \%)$.However, there is relative congruence in the weighting of Information Management across the 4 curricula.

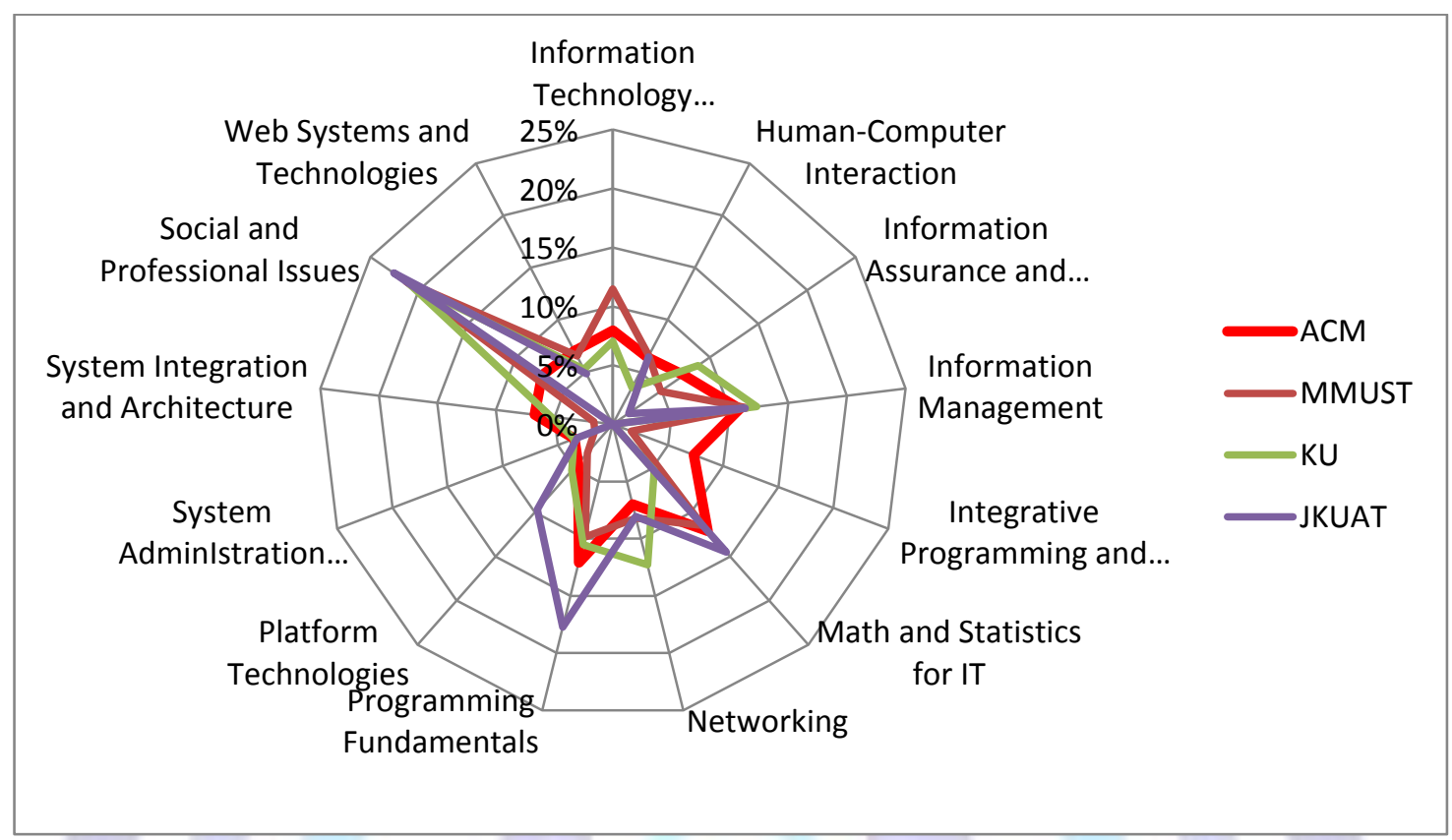

Figure 3.5: Relative Percent weight (core hours) in IT - ACM vs Respondents

The ACM and AICTE IT curricula are graphically disparate (Figure 3.6) with minimal overlapping knowledge areas. AICTE IT curriculum is shown to give major importance to hard engineering and science disciplines (i.e. Chemistry, Physics, and Thermodynamics) while ACM IT curriculum puts emphasis on Programming Fundamentals. Further, AICTE puts emphasis on Business and Marketing, which is treated vaguely in the ACM curriculum. Arguably, the Indian curriculum tends toward an instrumental education, which focuses on the current job market while the ACM is fairly liberal with a focus on intellectual attainment (Ezer, 2006)

\section{Comparing ACM and AICTE IT curricula}

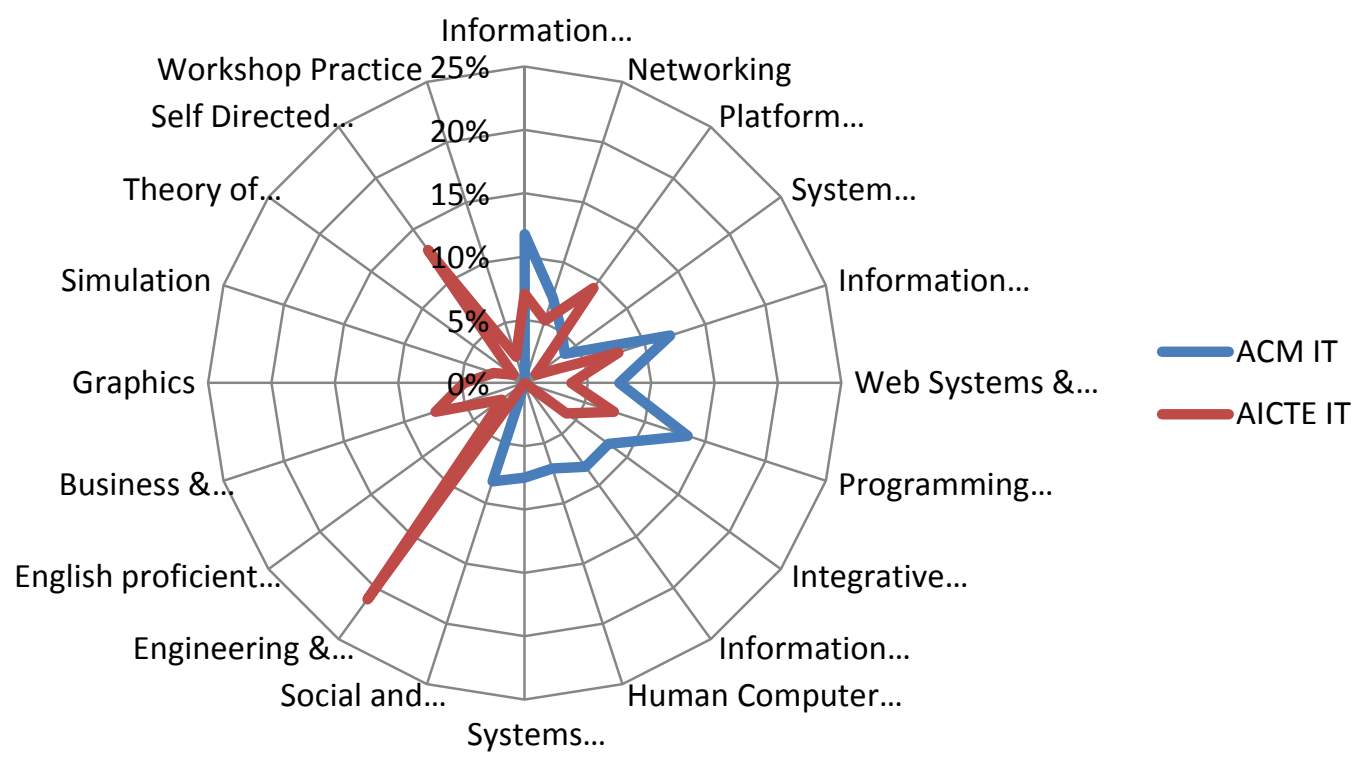

Figure 3.6: ACM (USA) and AICTE (India) IT curricula comparison (Source: Ezer, 2006) 


\section{ii. Relative performance capabilities of Computing graduates}

A list of 59 performance capabilities across 11 categories (ACM and IEEE-CS, 2006) was administered through a questionnaire where the respondents assigned a valued from $0-5$ against each discipline. The value 0 represented no expectation whatsoever, while 5 represented highest relative expectations.

\section{a. Computer Science}

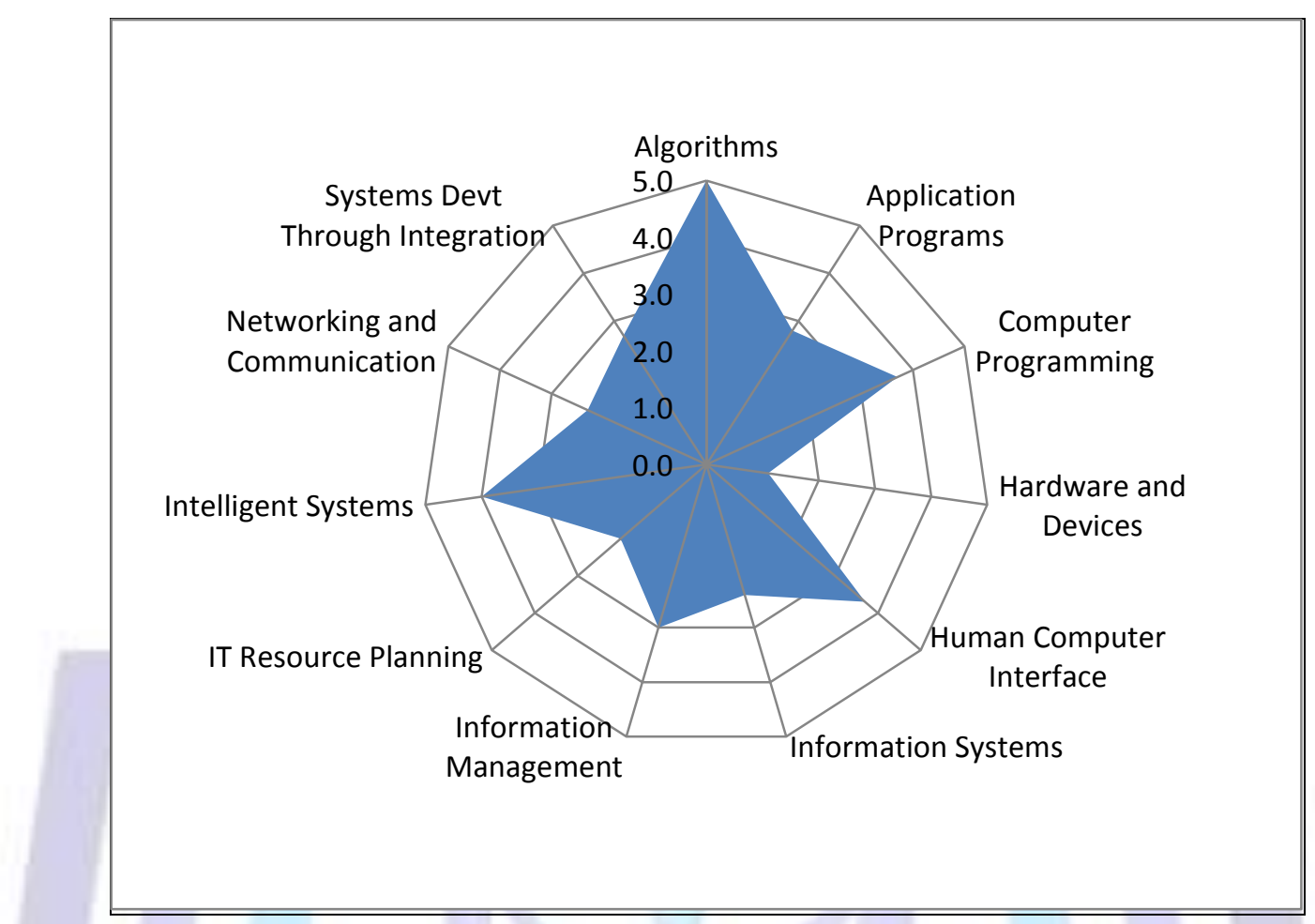

Figure 3.7: Relative performance capabilities of CS graduates - ACM

Figure 3.7 shows that according to ACM, CS graduates should be prepared to work in a broad range of positions involving tasks from theoretical work to software development. As a result, its highest relative competency expectations are in Algorithms and Intelligent Systems. Notably, the competence area of Hardware and Devices has the least expectation as it falls in the discipline of Computer Engineering.

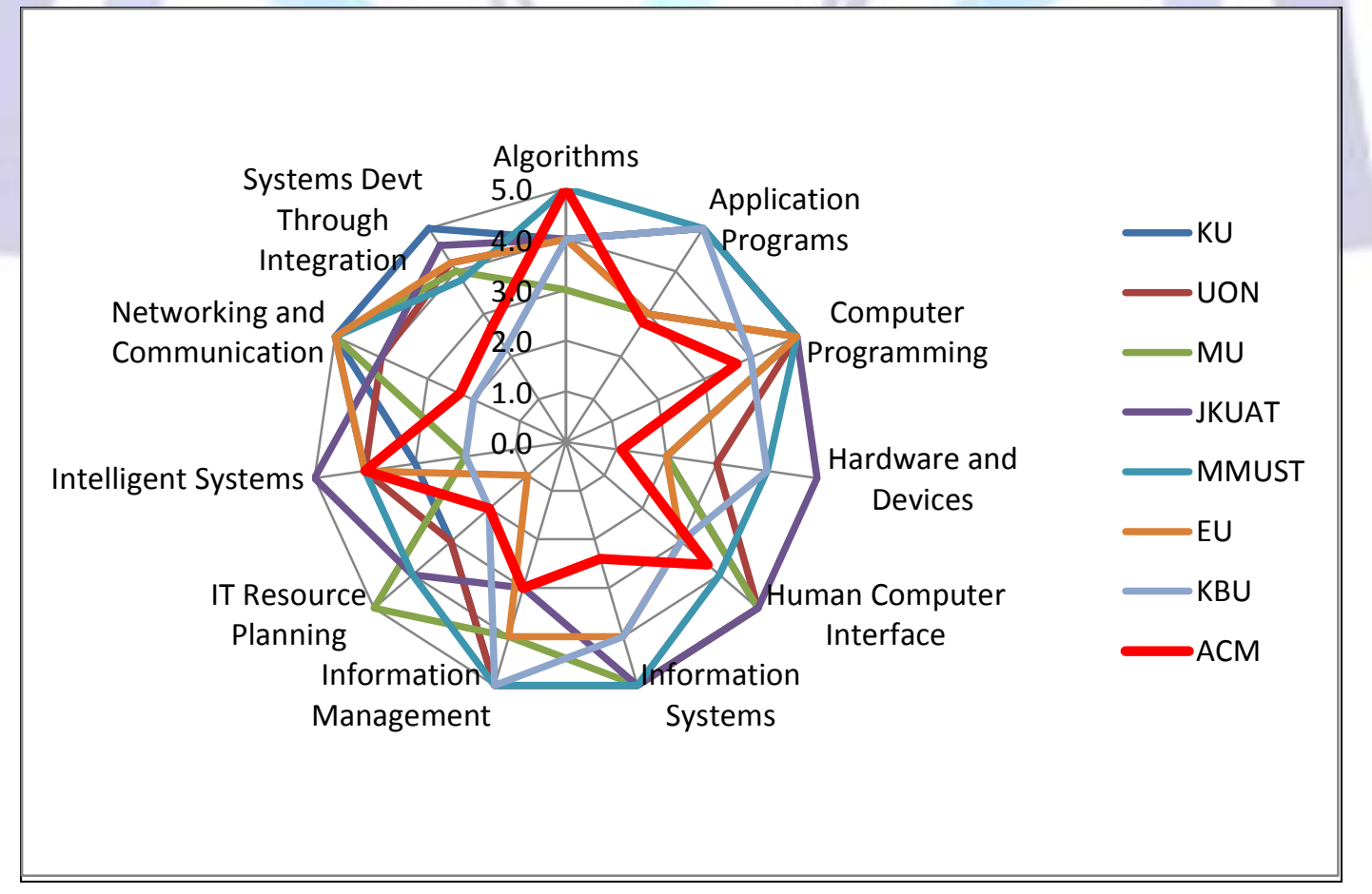

Figure 3.8: Competence area expectations for CS graduates - Respondents 


\section{Acronyms}

Moi University (MU); Kabarak University (KBU)

Figure 3.8 shows the respondents' expectations of their CS graduates. Inadvertently, great disparities are observed across the test curricula and against the ACM curricula. For instance the respondents indicated high expectations in Application Programs and Computer Engineering, unlike in ACM. This difference alludes to two possibilities: (i) the integration of CE and SE components into the CS curricula and (ii) the tension between an Instrumental and Liberal Education. By contrast the US based ACM curriculum has the luxury to offer a more liberal education, unlike Kenya which is a developing economy.

\section{b. Information Technology}

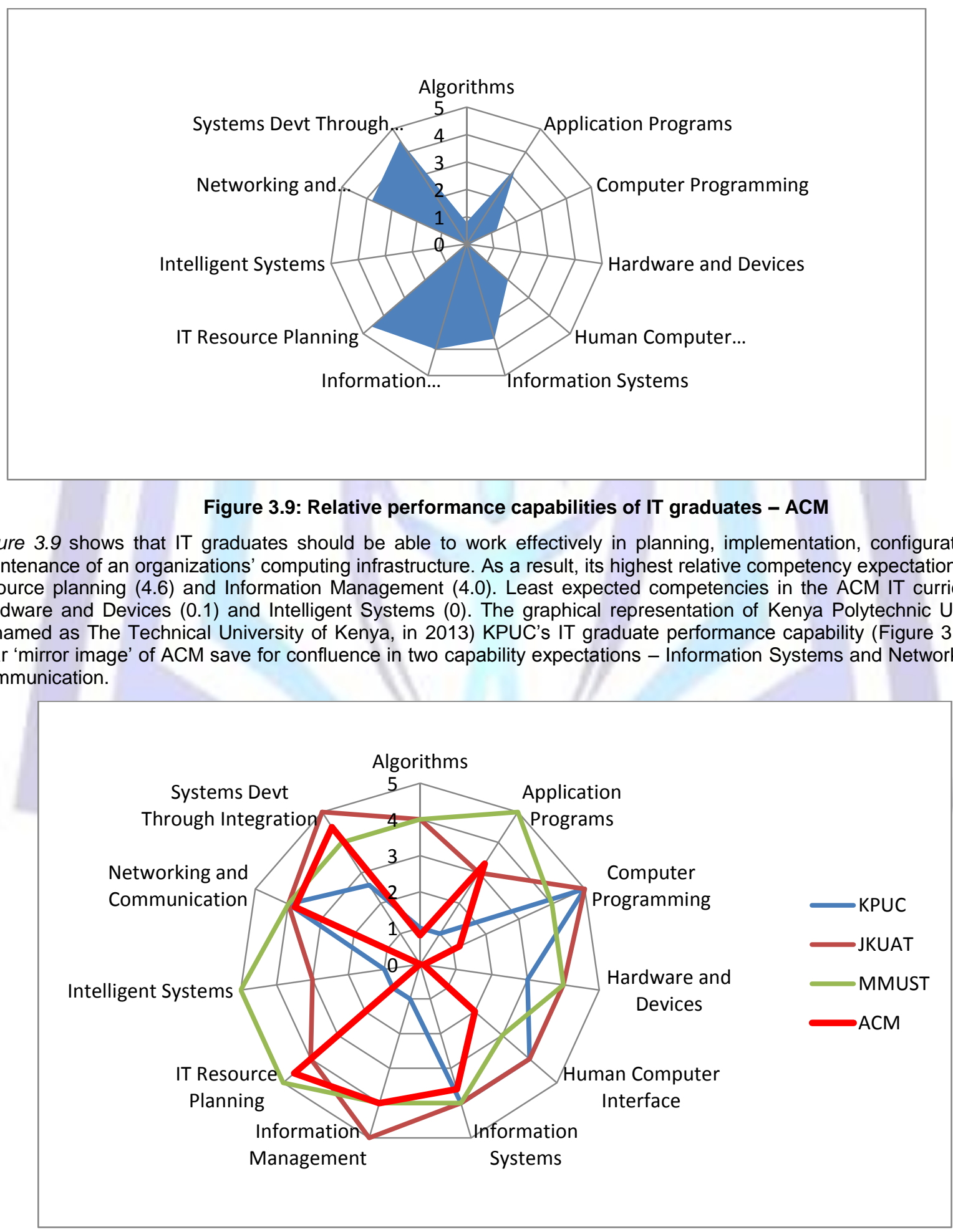

Figure 3.10: Relative performance capabilities of IT graduates - ACM \& Respondents 


\section{CONCLUSION}

In view of the foregoing, the study arrived at the following conclusions:

i. There is growth in the computing disciplines beyond the traditionally 5 programs, with CS and BBIT being popular in the public and private institutions, respectively.

ii. There are relative content/structural differences among the various CS and IT curricula.

iii. There are overlaps in the knowledge areas and competency expectation of graduates in CS and IT.

\section{RECOMMENDATIONS}

In view of the foregoing findings and conclusions, the study recommends the following:

i. Universities need to re-focus their computing programs in order to provide distinct knowledge and skills that are in tandem with Vision 2030 and global competitiveness. They should also promote collaborative benchmarking so as to obviate the feeling of competition and to fast track the process of integration and harmonization in HEls.

ii. The Government should consider establishing a regulatory body and qualifications framework for computing education and skills that will provide a benchmark/standard for all tertiary education besides promoting students' and marketability of graduates.

iii. Employers in the ICT industry should be aware of the institutional differences between computing programs and as such should not solely rely on undergraduate computing qualifications in their recruitment processes.

iv. Prospective students should appreciate the relative content/structural differences among the various CS and IT curricula and their offering institutions, hence the need to interrogate their desired programs of study vis-à-vis their ambitions.

v. Researchers could further test and refine the developed benchmarking tool and consider testing the excluded parameters (e.g. taught / assessed curricula, other levels of study and stakeholder perceptions) in similar studies.

\section{REFERENCES}

[1] ABET, (2011), Criteria for Accrediting Computing Programs; Effective for Evaluation During the 2008-2009 Accreditation Cycle, ABET Inc. Baltimore

[2] ACM and IEEE-CS (2008a) Computer Science Curriculum 2008: An Interim Revision of CS 2001, Report from the Interim Review Task Force, ACM and IEEE-CS press, USA http://www.acm.org/education/curricula/ComputerScience2008.pdf

[3] ACM and IEEE-CS, (2006) Computing Curricula 2005: An Overview Report covering undergraduate degree programs in Computer Engineering, Computer Science, Information Systems, Information Technology, and Software Engineering. http://www.acm.org/education/curricu_vols/CC2005-March06Final.pdf

[4] ACM and IEEE-CS, (2008b) Barry M. Lunt (Chair) Joseph J. Ekstrom Sandra Gorka Gregory Hislop Reza Kamali Eydie Lawson Richard LeBlanc Jacob Miller Han Reichgelt (Eds.), Information Technology 2008; Curriculum Guidelines for Undergraduate Degree Programs in Information Technology, ACM and IEEE-CS press, USA

[5] Alemneh D and Hastings S., (2006) Developing the ICT Infrastructure for Africa: The Influence on Global Scholarship, Journal of Education for Library and Information Science, Vol. 47, No. I, pp. 4-16

[6] Alstete, J. W. (1995), Benchmarking in Higher Education: Adapting Best Practices to Improve Quality. ASHE-ERIC Higher Education Report No. 5. USA

[7] Bankel, J. Berggren K, Engstrom M. Wiklund I. Crawley E. Soderholm D. Gaidi K. and Ostlund S. (2005) Benchmarking Engineering Curricula with the CDIO Syllabus, International Journal Engineering, Vol. 21, No. 1 pp. 121-133, TEMPUS Publications, Great Britain

[8] Borzovs J. (2004) What Computing Curricula is Needed: A Cast at the University of Latvia, Informatics in Education, Vol. 3, No. 1, pp. 31-42, Latvia

[9] BPO-STF, (2010) BPO.KPO Skills Gap Assessment Report For Kenya, Ministry of Information and Communication Technology, Nairobi

[10] Bridgland A. and Goodacre C. (2003) Benchmarking in Higher Education: A Framework For Benchmarking For Quality Improvement Purposes, Unpublished work, Australia

[11] Buckner, E., (2011), The Role of Higher Education in the Arab State and Society: Historical Legacies and Recent Reform Patterns, Comparative \& International Higher Education, Vol. 3, Spring 2011, The Official Newsletter of the Higher Education SIG, USA

[12] Camp R. and Andersen B., (2004), Current position and future development of benchmarking, Unpublished article

[13] Camp, R., (1989) Benchmarking: The Search for Industry Best Practices That Lead to Superior Performance, Milwaukee, Wisc.: American Society for Quality Control Press, USA

[14] CHEPS (2008) The first decade of working on the European Higher Education Area, The Bologna Process Independent Assessment Volume 1 Detailed assessment report 
[15] CHE (2012) Academic programmes approved by the Commission for private universities, Kenya, http://www.che.or.ke/status.html Accessed in July 2012

[16] CSK (2006) The National ICT Workforce Skills Demand Survey Report, Nairobi

[17] Dutta, S., Lanvin, B. and F. Paua (eds.), 2003. The Global Information Technology Report 2002-2003. Oxford University Press: New York.

[18] Ezer, J. (2006) India and the USA: A Comparison through the Lens of Model IT Curricula, Journal of Information Technology Education, Vol. 5, London

[19] Farquhar, H. (1998). "Higher Education Benchmarking in Canada and the United States of America", Schofield, A. (Ed.) Benchmarking in Higher Education: An International Review, CHEMS, London and UNESCO, Paris.

[20] Frailey, D. Ardis, M. and Hutchison N. (ed.s), (2009) Comparisons of GSwE2009 to Current Master's Programs in Software Engineering, Integrated Software \& Systems Engineering Curriculum Project, Stevens Institute.

[21] Government of Kenya (GOK)., (2007), Kenya Vision 2030 A Globally Competitive and Prosperous Kenya, Government Printers, Nairobi

[22] IDC (2011) Market ICT Indicator Survey Launch Report, Nairobi

[23] Kashorda, M. (2006), Emerging trends in Computing education in Kenyan Universities. Strathmore University ICT Conference Proceeding, Nairobi

[24] Lacrin S. and Karkkainen K., (2009), Educational Research and Innovation Higher Education to 2030, Volume 2, Globalization. IMHE News, OECD Publishing

[25] Magutu P. Mbeche I. Nyamwange S. and Nyaoga R., (2011), A Survey of Benchmarking Practices in Higher Education in Kenya: The Case of Public Universities, Vol. 2011, IBIMA Business Review

[26] OECD (2011), "A Tuning-AHELO Conceptual Framework of Expected Desired/Learning Outcomes in Engineering", OECD Education Working Papers, No. 60, OECD Publishing. http://dx.doi.org/10.1787/5kghtchn8mbn-en

[27] Porter C. and Smithson L., (2001) Defining, Developing, and Using Curriculum Indicators, Consortium for Policy Research in Education Research Report Series RR-048, USA

[28] Schofield, A. (1998). "An Introduction To Benchmarking In Higher Education”, Benchmarking in Higher Education: An International Review, CHEMS, London and UNESCO, Paris.

[29] Tuning Africa, (2011), Feasibility study into the relevance of a Tuning approach for Higher Education in Africa, Final Report, Tuning press

[30] Ventures Africa (2012): http://www.ventures-africa.com/2012/08/bridging-kenyas-ict-skills-gap/ Accessed $13^{\text {th }}$ October 2012)

[31] Waema T. (2002) ICT Human Resource Development in Africa: Challenges and Strategies, African Technology Policy Studies Network, PAPER SERIES No. 10, Kenya

[32] Waema T. (2005) In Etta, F.E. and Elder, L. (eds.), A Brief History of the Development of ICT Policy in Kenya. (At the Crossroads: ICT Policy Making in East Africa, pp. 25-43). Nairobi, Kenya: East African Educational Publishers Ltd.

\section{Authors' biography with photo}

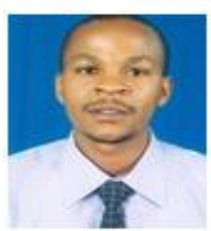

Mr. Joseph Mungai conducted the research as part of his Thesis for MSc Information Systems, undertaken at the school of Computing and Informatics, University of Nairobi. He holds a BSc. degree in Biomedical Science and Technology from Egerton University. Currently, he is a Programme Coordinator with Africa Educational Trust, an International NGO where he manages donor funded Educational programmes in countries affected by Conflict, including Somalia and South Sudan. He has research and academic interests in Computation Biology / Bioinformatics, Health Informatics and ICT for Development.

Dr. Wanjiku Ng'ang'a supervised this research. She is a senior faculty member at the School of Computing and Informatics, University of Nairobi, where she is actively involved in research as well as

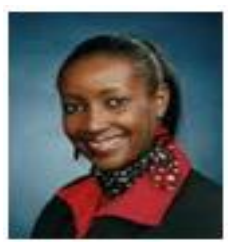
teaching and supervision of undergraduate and postgraduate research projects. She holds a doctorate degree from the University of Helsinki, Finland, an M.Phil degree from Cambridge University, UK, and a Bachelors degree in Computer Science from the University of Nairobi. She is the co-ordinator of the Computing for Development lab (C4DLab) that is active in ICT-related R\&D, and which is housed at the School of Computing \& Informatics in the Chiromo Campus of the University of Nairobi. Dr. Ng'ang'a's research interests span e-Governance, Technology-supported learning and training, the Knowledge Economy, Health Informatics and Machine Learning. 